\title{
Immunosuppressive and immunomodulatory therapy for inflammatory bowel disease
}

\author{
CHARles N BERNSTEIN, MD, FRCPC, FERGUS SHANAHAN, MD FRCPC
}

C BERNSTEIN, F SHANAHAN. Immunosuppressive and immunomodulatory therapy for inflammatory bowel disease. Can J Gastroenterol 1993;(2):115. 120. Identification of the mechanisms and mediators involved in the pathogenesis of inflammatory bowel disease (IBD) has provided a sound rationale for the therapeutic use of immunosuppressive agents and has led to novel therapeutic approaches. The efficacy of traditional immunosuppressives such as the purine analogues (azathioprine/6-mercaptopurine) in both Crohn's disease and ulcerative colitis is now well established. However, the slow onset of clinical efficacy associated with purine analogues has prompted the investigation of other immunosuppressives such as cyclosporine and FK506 that have a more rapid onset of action. While early results appear promising, the exact role of these agents requires more investigation. Because of the potential for long term toxicity, many clinicians view the role of cyclosporine as an interim measure for acutely ill patients. More recent immunomodulatory approaches to IBD have been selected, not on the basis of empiric observation, but because of an improved understanding of the immunopathogenesis of these disorders. Novel approaches that are in an early phase of investigation include the modulation of cytokines and their receptors, inhibition of mucosal antigen processing and presentation, and the use of monoclonal antibodies targeted to specific mucosal effector lymphocytes.

Key Words: Crohn's disease, Immunomodulation, Immunosuppressive therapy, Inflammatory bowel disease, Ulcerative colitis

\section{Traitement immunosuppresseur et immunomodulateur de la maladie intestinale inflammatoire}

RÉSUMÉ: L'identification des mécanismes et des médiateurs en jeu dans la pathogenèse de la maladie intestinale inflammatoire a justifié le recours thérapeutique à des agents immunosuppresseurs et permis l'élaboration de nouvelles approches thérapeutiques. L'efficacité d'immunosuppresseurs classiques, comme les antipurines (azathioprine/6-mercaptopurine), tant dans la maladie de Crohn que dans la colite ulcéreuse, est désormais reconnue. Cependant, la lente survenue de l'amélioration clinique associée aux antipurines a donné lieu à une recherche sur d'autres immunosuppresseurs, comme la cyclosporine et le FK-506

University of California, School of Medicine, Los Angeles, California, USA

Correspondence and reprints: Dr F Shanahan, Division of Gastroenterology, Room 44.138, UCLA Center for the Health Sciences, 10833 Le Conte Avenue, Los Angeles, CA 90024 ,

USA. Telephone (310) 825-0174, Fax (310) 825-7067
W HILE THE CAUSE(S) OF INFLAMmatory bowel disease (IBD) remains unclear, advances in understanding of the mechanisms and mediators involved in the pathogenesis have provided a sound rationale for the therapeutic use of immunosuppressants and have led to novel therapeutic approaches $(1,2)$. The basis of immunosuppressive therapy in both Crohn's disease and ulcerative colitis is as follows: there is general agreement that the immune system mediates the tissue damage in these disorders; and while environmental factors including infectious agents might be disease triggers in genetically susceptible individuals, there is no convincing evidence for any ongoing infection in either condition.

An overview of newer immunomodulatory agents that may have an important role in the management of IBD in the future is presented. Representative examples of potential immunomodulatory strategies for IBD are illustrated in Figure 1. Traditional immunosuppressives such as the purine analogues have been reviewed in detail elsewhere $(3,4)$ and their role in IBD will be summarized.

\section{PURINE ANALOGUES}

(AZATHIOPRINE AND

6-MERCAPTOPURINE)

Azathioprine is the S-imidazole precursor of 6-mercaptopurine (6-MP) and was developed with the intent of 
dont l'action débute plus rapidement. Bien que les résultats préliminaires semblent prometteurs, le rôle exact de ces agents requiert des recherches plus approfondies. À cause de sa toxicité potentielle à long terme, plusieurs cliniciens voient le rôle de la cyclosporine comme une mesure intérimaire pour les patients en phase aiguë. Les approches plus récentes par immunomodulation dans la maladie intestinale inflammatoire ont été sélectionnées, non sur la base de l'observation empirique, mais sur la base d'une meilleure compréhension de l'immunopathogenèse de ces maladies. Les nouvelles approches, qui en sont à leur première phase de recherche, incluent la modulation des cytokines et de leurs récepteurs, l'inhibition du traitement et de la présentation des antigènes muqueux et le recours aux anticorps monoclonaux dirigés spécifiquement contre les lymphocytes effecteurs de la muqueuse.

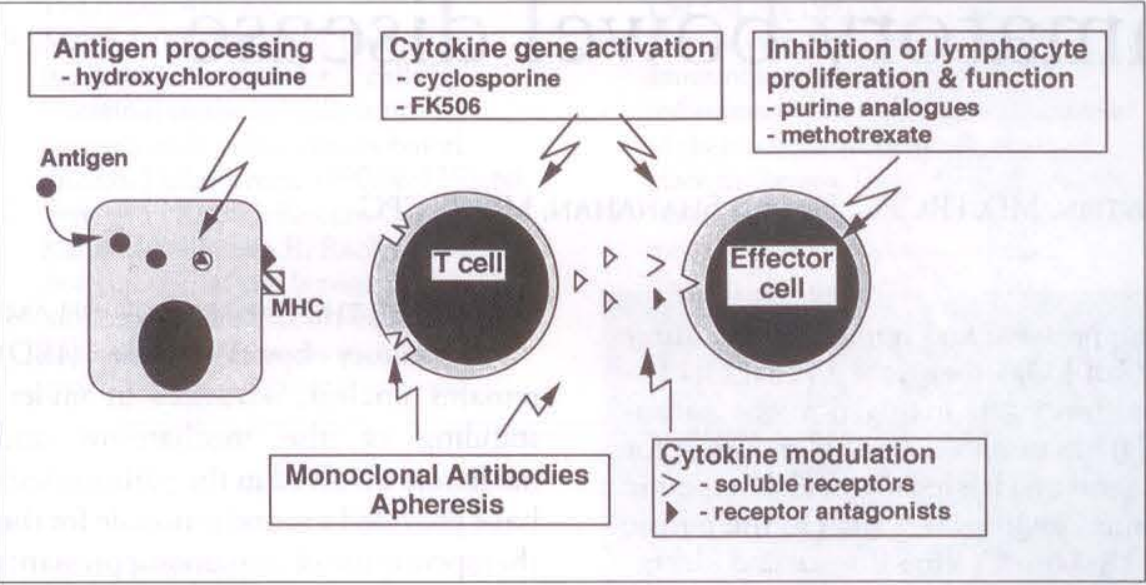

Figure 1) Schematic representation of potential immunomodulatory therapeutic strategies for inflammatory bowel disease

achieving a delayed release of the active moiety. Azathioprine and 6-MP inhibit purine nucleotide biosynthesis and interconversion. These are important steps in inhibiting DNA and RNA synthesis and cell proliferation. These drugs act at crucial steps in $B$ and $T$ cell activation, blocking gene activation and proliferation. Although the drugs probably have similar efficacy and toxicity, there is a paucity of comparative data.

Early controversy about the use of purine analogues in IBD was related primarily to conflicting results found in some early trials, including the National Cooperative Crohn's Disease Study (5). Limitations in the design of early studies, particularly the failure to account for the slow onset of clinical efficacy of purine analogues, were subsequently recognized. These agents require a median of three months before clinical efficacy is apparent. This implies that they are not likely to be useful for acutely ill patients and that other medications such as steroids should not be withdrawn while initiating this form of immunosuppressive therapy.

The most convincing evidence for the efficacy of 6-MP in the treatment of active Crohn's disease was a landmark study by Present and colleagues in 1980 (6). This double-blind, placebo controlled study over a period of two years avoided the limitations of earlier studies. Instead of a disease activity index, specific treatment goals for each patient were used to determine efficacy. Treatment goals are more practical and parallel usual clinical practice more closely than a calculated score. 6-MP proved to be effective compared with placebo in terms of improvement of clinical status, reduction in concurrent corticosteroid use and closure of fistulas. While the role of purine analogues in ulcerative colitis is less rigorously defined, there is evidence for therapeutic efficacy, and these agents offer a steroid-sparing effect and a reasonable alternative when surgery is undesirable or risky $(3,4)$.

The most convincing evidence for the role of azathioprine/6-MP as a maintenance therapy in the prevention of relapses in patients with quiescent disease comes from double-blind, placebo controlled withdrawal trials in both Crohn's disease (7) and ulcerative colitis (8). In both of these studies, patients who were withdrawn on to placebo had a significantly higher frequency of relapses than those who remained on azathioprine.

Purine analogues are remarkably well tolerated. Concerns about long term toxicity are appropriate but not well substantiated to date. Recommended daily doses for patients with IBD for both drugs have been in the range of 1 to $2 \mathrm{mg} / \mathrm{kg}$, although a dose of $50 \mathrm{mg}$ of $6-\mathrm{MP}$ appears to be sufficient for most patients. At these doses, toxicologically significant marrow sup. pression is rare. In a long term study of almost 400 patients, severe infections were observed in $1.8 \%$ and pancreatitis occurred in $3.3 \%(9)$. The occurrence of pancreatitis is usually within the first month of therapy. It appears to be due to a hypersensitivity phenomenon and precludes further use of either 6-MP or azathioprine. A syndrome of variable severity involving fever, malaise and arthralgia without eosinophilia has also been reported (10).

An important theoretical risk to long term use of purine analogues is the potential for development of malignancy, particularly lymphoma. Although there are published reports of two patients who developed central nerv. ous system lymphoma in Crohn's disease while receiving purine analogue therapy (3), and lymphoma is a known risk of immunosuppressive therapy, there is no clear relationship between cancer and azathioprine/6-MP use in IBD (9). Whether purine analogues have an adverse effect on the outcome of pregnancy is also uncertain $(3,4)$. Dayan et al (11) reported on three groups of women of childbearing age using 6-MP either before conception, at conception or after completion of pregnancy. There was no difference in premature births or congenital anom. 
alies among the first two groups compared with the third. Despite the absence of evidence for an adverse effect of 6-MP or azathioprine on the outcome of pregnancy, it remains prudent to advise against its use before or during conception, or during gestation.

\section{CYCLOSPORINE}

Cyclosporine is a highly lipid soluble neutral cyclic polypeptide consisting of 11 amino acids. The impact of this drug on the outcome of organ transplantation has been revolutionary. In the past several years, it has also been tested in many autoimmune diseases, usually in the more refractory cases. Its role in $\mathrm{IBD}$ is at an early stage of investigation.

The action of cyclosporine is lymphocyte specific, noncytotoxic and reversible and it avoids the myelotoxic side effects of agents like 6-MP. It acts particularly on T cell function and proliferation, mainly through inhibition of interleukin (IL)-2 gene transcription and thus diminution of IL-2 release (12-14). This leads to an inhibition of helper $T$ cell function and secondarily there is a loss of recruitment and expansion of effector $\mathrm{T}$ cells and $\mathrm{T}$ celldependent immunological events. Release of other cytokines such as gamma-interferon, IL-3 and IL-4 is also inhibited. Interestingly, cyclosporine seems to spare the action and development of suppressor $T$ cells.

In contrast to other immunosuppressants, the appropriate dose of cyclosporine is highly variable, requires close monitoring and blood levels are an essential guide. In this respect, an understanding of the pharmacokinetics of cyclosporine is important. Oral absorption of cyclosporine is slow and incomplete and takes place in the small intestine. Recent data indicate that the small intestine is also a major site of cyclosporine metabolism (15). Active intestinal disease or short gut syndrome will limit cyclosporine absorption, as can other causes of impaired fat absorption. Once absorbed, cyclosporine is highly bound to blood proteins. Since approximately $80 \%$ is bound to lipoproteins, the lipoprotein profile of a particular patient will influence blood concentrations. The drug also binds to red blood cells and thus changes in hematocrit will have a similar effect. These binding properties explain why blood and plasma or serum levels are so discordant. The whole blood concentrations are usually twice that of plasma concentrations and are more reliable. Radioimmunoassay levels are consistently greater than those detected by high performance liquid chromatography because the drug's metabolites react with the polyclonal antibody to cyclosporine in the radioimmunoassay.

In addition to the small intestine, the other main site of cyclosporine metabolism is the cytochrome P-450 system of the liver. Metabolites are concentrated in the bile and alterations in bile flow can, therefore, influence cyclosporine levels. There is little renal excretion and dose adjustments are not necessary in chronic renal failure or in patients on hemodialysis (the drug is also not removed by dialysis). Drugs that affect the cytochrome P-450 system will have an important effects on cyclosporine levels.

The first report on the use of cyclosporine in IBD appeared in 1984 (16). In the ensuing years, many reports of open trials of cyclosporine in both Crohn's disease and ulcerative colitis have been reported. As with other immunologically mediated diseases, use of this drug has generally been limited to patients with severe disease. The main advantage of cyclosporine is that clinical improvement, when it occurs, is usually rapid within days to weeks, in contrast to months with 6-MP and azathioprine. In this respect, cyclosporine may have an important role on a short term basis while treatment with another less toxic agent such as 6-MP is being initiated.

In the first published placebo controlled, double-blind trial with cyclosporine, Brynskov et al (17) used cyclosporine $A$ orally ( 5 to $7.5 \mathrm{mg} / \mathrm{kg} /$ day) in patients with active and resistant Crohn's disease. At the end of three months, $59 \%$ of patients improved by a clinical scale versus $32 \%$ of patients receiving placebo $(\mathrm{P}=0.032)$. However, the degree of clinical improvement was mild and was associated with a significant relapse rate after drug withdrawal. The investigators might have achieved more significant improvement with cyclosporine had they initiated the trial with an intravenous dosing schedule. In contrast, a preliminary report of a multicentre Canadian study indicated that cyclosporine at a dosage of $4.8 \mathrm{mg} / \mathrm{kg}$ is ineffective both as therapy and for maintenance of remission (18).

Lichtiger and Present (19) reported the largest series of patients with ulcerative colitis treated with cyclosporine. Using intravenous cyclosporine $(4 \mathrm{mg} /$ $\mathrm{kg} /$ day) in patients who were refractory to intravenous steroids, they achieved a clinical improvement in 11 of 15 patients such that the need for colectomy was avoided. The most impressive finding was the rapidity of the clinical response, with a mean response time of only six days. If these exciting results are confirmed in a controlled setting, the approach to patients with severe or fulminant colitis who are not medically or psychologically ready for colectomy may soon be very different.

The route of administration of cyclosporine to patients with IBD requires careful consideration and will vary, depending on the distribution of disease and the urgency of the clinical circumstances. The variable absorption in Crohn's disease requires that the clinician pay particular heed to drug levels whereas oral absorption may be less at issue in ulcerative colitis. In acutely ill patients, particularly those with Crohn's disease, therapy initiation by the intravenous route is preferable. For patients with ulcerative proctosigmoiditis, the role of topical cyclosporine by enema has been proposed but results are still very preliminary (3).

The most prominent side effect of cyclosporine is nephrotoxicity which may occur in an acute or chronic form and is particularly more common in patients taking nephrotoxic drugs concurrently $(3,12)$. In more than $90 \%$ of patients, the renal dysfunction will be reversible upon discontinuing the drug. However, irreversible diffuse interstitial fibrosis after prolonged use has been reported. Other metabolic problems seen with cyclosporine use include hy. perkalemia, hyperuricemia and hepato- 
toxicity. Additional common side effects include hypertrichosis, gingival hyperplasia, tremors and paraesthesia. Most of the side effects are reversible upon stopping or reducing the dose of cyclosporine. Seizures and anaphylaxic reactions to the diluent in the intravenous infusion have been recorded.

\section{FK506 AND RAPAMYCIN}

FK506 and rapamycin are macrolide antibiotics that have been used in the solid organ transplantation setting. They are lipophilic and, like cyclosporine, require intact small intestinal fat absorption. The mechanism of action of these two agents is very similar to that of cyclosporine, although they are both much more potent than cyclosporine.

FK506 has been reported to be an effective rescue therapy in liver transplant patients who are unresponsive to conventional immunosuppression, including cyclosporine $(20,21)$. In addition to improved graft survival, it is hoped that FK506 will be associated with fewer side effects, although this remains to be proved. There are no published reports of the use of FK506 in patients with IBD. FK506 has been reported to be effective in various animal models of autoimmune disease (3). Rapamycin has been shown to inhibit adjuvant arthritis and experimental allergic encephalitis in rats and can suppress both graft versus host and host versus graft reactions (3).

\section{METHOTREXATE}

Methotrexate is a folic acid antagonist that exerts its effect only during the DNA synthesis phase of the cell cycle. Thus, the drug has an inhibitory effect on proliferating cells, while sparing resting cells. In contrast to cyclosporine, monitoring blood levels is not an important clinical consideration with methotrexate. At oral doses below $30 \mathrm{mg} / \mathrm{m}^{2}$, methotrexate is nearly completely absorbed from the gastrointestinal tract.

Over the past 20 years methotrexate has gained widespread use in the treatment of several chronic inflammatory conditions although there are no published placebo-controlled studies of its use in IBD. In a preliminary open trial ( $25 \mathrm{mg}$ intramuscularly, weekly for 12 weeks) in patients who were refractory to other treatments including 6-MP, objective evidence for improvement was found in 11 of 14 patients with Crohn's disease and five of seven patients with ulcerative colitis (22). A significant steroid-sparing effect was also observed. Overall, the clinical response was most marked in Crohn's colitis, with five of seven patients achieving endoscopically confirmed remission. The same group of investigators continue to update their experience with methotrexate in IBD and report a response rate of approximately $70 \%$ in Crohn's disease but with much less impressive results in ulcerative colitis. Controlled clinical trials are now underway.

Toxicity with methotrexate has, in general, been mild and included transient serum transaminase elevations, leucopenia and, rarely, hypersensitivity pneumonitis. If the efficacy of methotrexate is confirmed in controlled studies, a controversial issue that should be addressed in these patients is the potential for hepatic fibrosis. The development of hepatic fibrosis appears to be related to the cumulative dose and the underlying disease. Published data from patients with psoriasis and rheumatoid arthritis treated with methotrexate appear to be discrepant with respect to the frequency of development of hepatic fibrosis, and the issue will need to be studied in patients with IBD.

\section{HYDROXYCHLOROQUINE}

Traditionally used as antimalarials chloroquine and hydroxychloroquine, also have a role in the management of some chronic inflammatory disorders including systemic lupus and rheumatoid arthritis. These agents interfere with many cellular functions by raising the $\mathrm{pH}$ within intracellular organelles. Recent use of these agents for IBD is based on the following rationale. Intestinal epithelial cells are capable of processing and presenting antigens to the mucosal immune system, and under normal circumstances this leads to stimulation of suppressor $\mathrm{T}$ cell activity. In IBD there is evidence for preferential stimulation of helper cells that might lead to the perpetuation of the inflammatory response (23). By inhibiting antigen processing by epithelial cells at the lysosomal level chloro. quine and hydroxychloroquine can reverse this defect in vitro.

Clinically, hydroxychloroquine is favoured over chloroquine because of an improved safety profile, particularly in relation to the potential for ocular toxicity. Preliminary uncontrolled studies of chloroquine and hydroxy. chloroquine have been promising in patients with ulcerative colitis but disappointing in Crohn's disease. Although hydroxychloroquine $(400$ $\mathrm{mg} /$ day for six weeks) did not have a statistically significant therapeutic effect when compared with placebo, a substantial subset of patients appeared to undergo a striking remission (24). Another trial with a higher dose of hydroxychloroquine $(800 \mathrm{mg} /$ day $)$ and for a longer period of treatment (eight weeks) is now planned (L Mayer, personal communication).

\section{T CELL APHERESIS}

Based on the premise that $T$ cells have an important contribution to the pathogenesis of IBD, T cell apheresis has been attempted in patients with Crohn's disease (25). While the results appear to be promising, they are still preliminary and unconfirmed. This procedure is unlikely to gain widespread acceptance because it is expensive, time consuming and may have a risk of viral transmission. In addition, an outcome similar to $T$ cell inactiva. tion or removal can probably be ac. complished in the future with monoclonal antibodies or cytokine in. hibitors.

\section{MONOCLONAL ANTIBODIES}

An increasing variety of monoclo. nal antibodies that recognize specific $T$ cell surface determinants has been used therapeutically in experimental animal models of autoimmune disease. Pilot trials with monoclonal antibodies directed against $T$ cell surface antigens have been reported in multiple sclerosis patients (26). In a preliminary open study of patients with active Crohn's 
disease using a monoclonal antibody to CD5 present on most T cells, no significant therapeutic benefit was observed (unpublished data). Future approaches will probably be directed at functionally distinct $T$ cell subsets, particularly activated T cells. Monoclonal antibodies to the IL-2 receptor have the theoretical advantage of leaving nonactivated lymphocytes intact. Anti-IL-2 receptor antibody has been shown to be effective in a mouse model of diabetes (27).

\section{INTRAVENOUS GAMMAGLOBULIN}

There are a number of anecdotal reports of a beneficial effect of intravenous gammaglobulin therapy in both Crohn's disease and ulcerative colitis (3). The precise mechanism of action is unknown. Although side effects are

ACKNOWLEDGEMENTS: The authors are supported by National Institute of Health grant DK 40057 and by the Blinder Foundation for Crohn's Disease Research.

\section{REFERENCES}

1. Shanahan F, Targan SR. Mechanisms of tissue injury in inflammatory bowel disease. In: MacDermott RP, Stenson WF, eds. Inflammatory Bowel Disease. Elsevier, New York; 1992:77-94.

2. Shanahan F, Targan SR. Medical treatment of inflammatory bowel disease. Ann Rev Med 1992;43:125-33.

3. Bernstein CN, Shanahan F. Immunomodulatory therapy in inflammatory bowel disease. In: Targan S, Shanahan F, eds. Inflammatory Bowel Disease: From Bench to Bedside. New York: Williams and Wilkins. (In press)

4. Present DH. 6-Mercaptopurine and other immunosuppressive agents in the treatment of Crohn's disease and ulcerative colitis. Gastroenterol Clin N Am 1989;18:57-71.

5. Singleton JW, Law DH, Delly ML Jr, et al. National Cooperative Crohn's Disease Study: Results of drug treatment. Gastroenterology 1979;77:847-69.

6. Present DH, Korelitz BI, Wisch N, Glass JL, Sachar DB, Pasternack BS. Treatment of Crohn's disease with 6-Mercaptopurine. A long term randomized double blind study. N Engl J Med 1980;302:981-7.

7. O'Donoghue DP, Dawson AM, Powell-Tuck J, Brown RL, generally mild and short lived, there remains a risk of possible transmission of nonhepatitis B viral hepatitis (28). Since the use of intravenous gammaglobulin is costly (the wholesale cost of intravenous immunoglobulin in the United States is US $\$ 35$ to $\$ 65 / g$ ) (28), a randomized controlled trial is necessary before this approach could be advocated even for cases refractory to conventional therapy.

\section{CYTOKINE MODULATION}

Cytokines are the molecular messengers that regulate the immune system and mediate its effector functions. Most of the known cytokines and their receptors have been molecularly cloned. The use of soluble cytokine receptors is currently being explored as a potential therapeutic approach to the interference with cytokine action. An

Lennard-Jones JE. Double blind withdrawal trial of azathioprine as maintenance treatment for Crohn's disease. Lancet 1978;ii:955-7.

8. Hawthome AB, Logan RFA, Hawkey $\mathrm{CJ}$, et al. Efficacy of azathioprine in maintaining remission in ulcerative colitis: A placebo controlled withdrawal trial. Gastroenterology 1991;100:A216.

9. Present DH, Meltzer SJ, Krumholz MP, Wolke A, Korelitz BI. 6-Mercaptopurine in the management of inflammatory bowel disease: Short and long term toxicity. Ann Int Med 1989;111:641-9.

10. Saway PA, Heck LW, Bonner JR, Kirklin JK. Azathioprine hypersensitivity. Am J Med 1988;84:960-4.

11. Dayan A, Rubin P, Chapman M. 6-Mercaptopurinc (6-MP) in inflammatory bowel disease (IBD) patients of childbearing age. No increase in congenital anomalies. A case controlled study. Gastroenterology 1991;100:A824.

12. Kahan B.D. Cyclosporine. N Engl J Med 1989:321:1725-38

13. Hodgson HJF. Cyclosporine in inflammatory bowel disease. Aliment Pharmacol Therapy 1991;5:343-50.

14. Cockfield SM, Halloran PF. Cyclosporine: A new decade. Ann RCPSC 1991;24:25-8.

15. Kolars JC, Awni WM, Merion RM, Watkins PB. First-pass metabolism of cyclosporin by the gut. Lancet 1991;338:1488-90.

16. Allison MC, Pounder RE. Cyclosporin for Crohn's disease. Lancet alternative approach is to use a receptor antagonist. IL-1 is the first and only cytokine to date for which a naturally occurring cytokine antagonist has been discovered and cloned $(29,30)$. IL-1 receptor antagonist (IL-1ra) blocks the activity of IL-1 by occupying IL-1 surface receptors without exhibiting any agonist activity. The IL-1 ra has proved useful in limiting the systemic effects of endotoxic shock in animal models (31) and in improving survival from graft versus host disease in a murine bone marrow transplant model (32). In addition, its effectiveness in two different animal models of colitis has recently been demonstrated $(33,34)$. It seems likely from these exciting early results that cytokine modulation may represent a novel approach to the management of IBD and other chronic inflammatory disorders in humans in the future.

1984:i:902-3.

17. Brynskov J, Freund L, Rasmussen SN. A placebo controlled, double-blind randomized trial of cyclosporine therapy in active chronic Crohn's disease. N Engl J Med 1989;321:845-50.

18. Archambault A, Feagan B, Fedorak R, et al. The Canadian Crohn's relapse prevention trial (CCRPT). Gastroenterology 1992;102:A591.

19. Lichtiger Present DH. Preliminary. report: Cyclosporin in treatment of severe active ulcerative colitis. Lancet 1990;ii:16-9.

20. Starzl TE, Todo S, Fung J, Demetris A], Venkataramman R, Jain A. FK506 for liver, kidney, and pancreas transplantation. Lancet 1989;ii:1000-4

21. Macleod AM, Thomson AW. FK506: An immunosuppressant for the 1990s? Lancet 1991;337;25-7.

22. Kozarek RA, Patterson DJ, Gelfand MD, Botoman VA, Ball TJ, Wilske KR. Methotrexate induces clinical and histologic remission in patients with refractory inflammatory bowel disease, Ann Int Med;1989;110:353-6.

23. Mayer L, Eisenhardt D. Lack of induction of suppressor T cells by intestinal epithelial cells from patients with inflammatory bowel disease. J Clin Invest 1990;86:1255-60

24. Mayer L, Sachar DB, Present DH, et al. Randomized, double-blind, placebo-controlled trial of hydroxychloroquine (Plaquenil) in the treatment of ulcerative colitis. Gastroenterology 1992;102:A661.

25. Bicks RO, Groshart KD. The current status of T-lymphocyte apheresis 
(TLA) treatment of Crohn's disease. J Clin Gastroenterol 1989;11:136-8. (Edit)

26. Hafler DA, Ritz J, Schlossman SF, Weiner HL. Anti-CD4 and anti-CD2 monoclonal antibody infusions in subjects with multiple sclerosis. J Immunol 1988;141:131-8.

27. Kelley VE, Gaulton GN, Hattori M, Ikegami H, Elsenbarth G, Strom TB. Anti-interleukin-2 receptor antibody suppresses murine diabetic insulinitis and lupus nephritis. J Immunol 1988;140:59-61.

28. Buckley RH, Scuff RI. The use of intravenous immune globulin in immunodeficiency diseases. N Engl ] Med 1991;325:110-6.

29. Larrick JW. Native interleukin-1 inhibitors. Immunol Today 1989;10:61-6.

30. Dinarello CA, Thompson RC. Blocking IL-1: Interleukin 1 receptor antagonist in vivo and in vitro. Immunol Today 1991;12:404-10.

31. Dinarello CA. The proinflammatory cytokines interleukin 1 and tumour necrosis factor and treatment of the septic shock syndrome. J Inf Dis 1991;163:1177-84.

32. McCarthy PL, Abhyankar S, Neben S, et al. Inhibition of interleukin-1 by an interleukin-1 receptor antagonist preventsgraft-versus-host-disease. Blood 1991;78:1915-8.

33. Cominelli F, Nast CC, Clark BD, et al. Interleukin-1 gene expression synthesis and effect of special IL-1 receptor blockade in rabbit immune complex colitis. J Clin Invest 1990;86:972-80.

34. Sartor RB, Holt LC, Bender DE, Murphy, ME, McCall RD, Thompson RC. Prevention and treatment of experimental enterocolitis with a recombinant interleukin-1 receptor antagonist. Gastroenterology 1991;100:A613. 


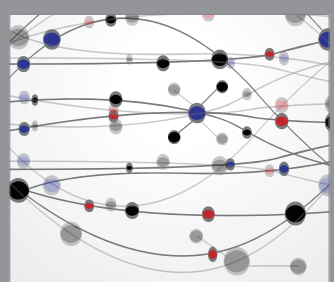

The Scientific World Journal
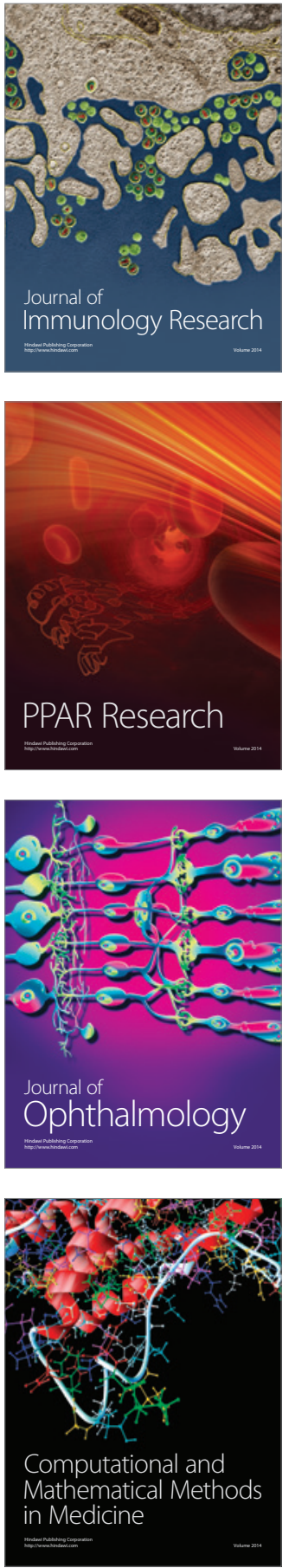

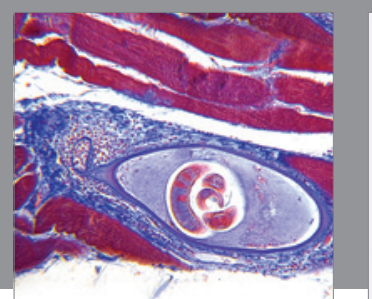

Gastroenterology Research and Practice

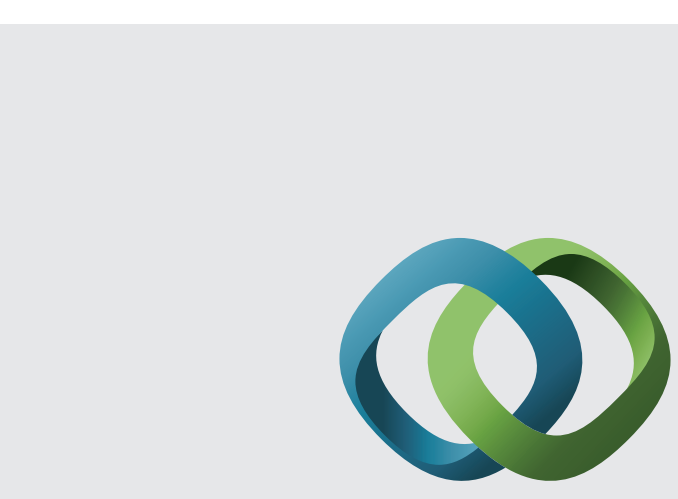

\section{Hindawi}

Submit your manuscripts at

http://www.hindawi.com
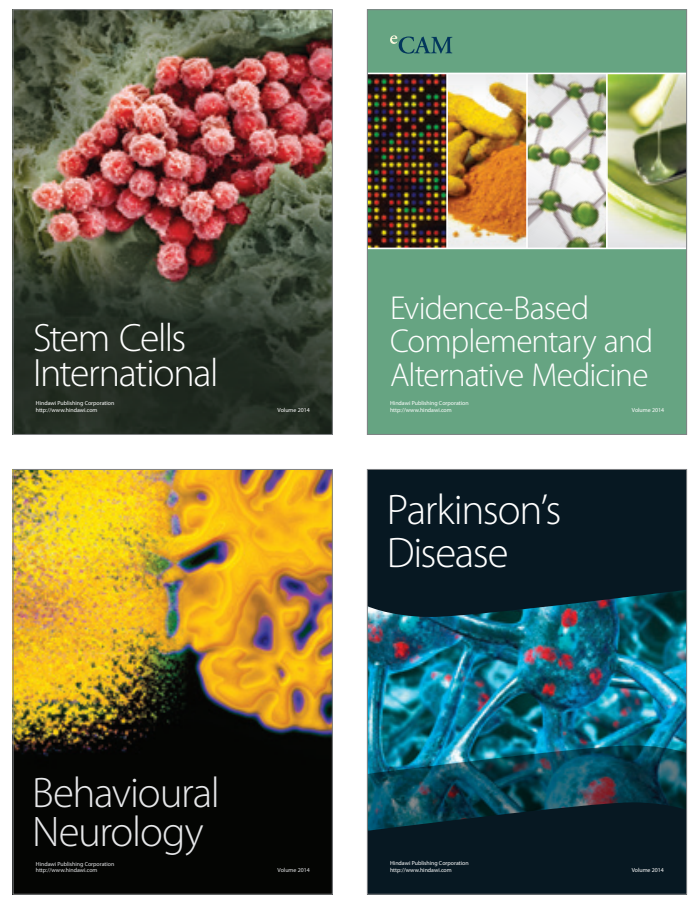
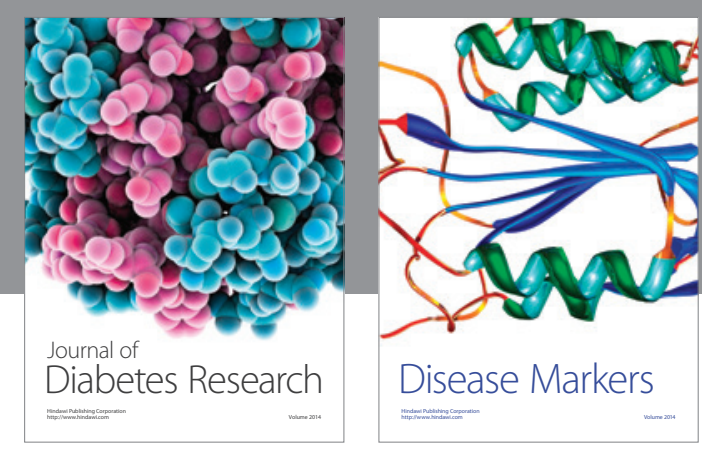

Disease Markers
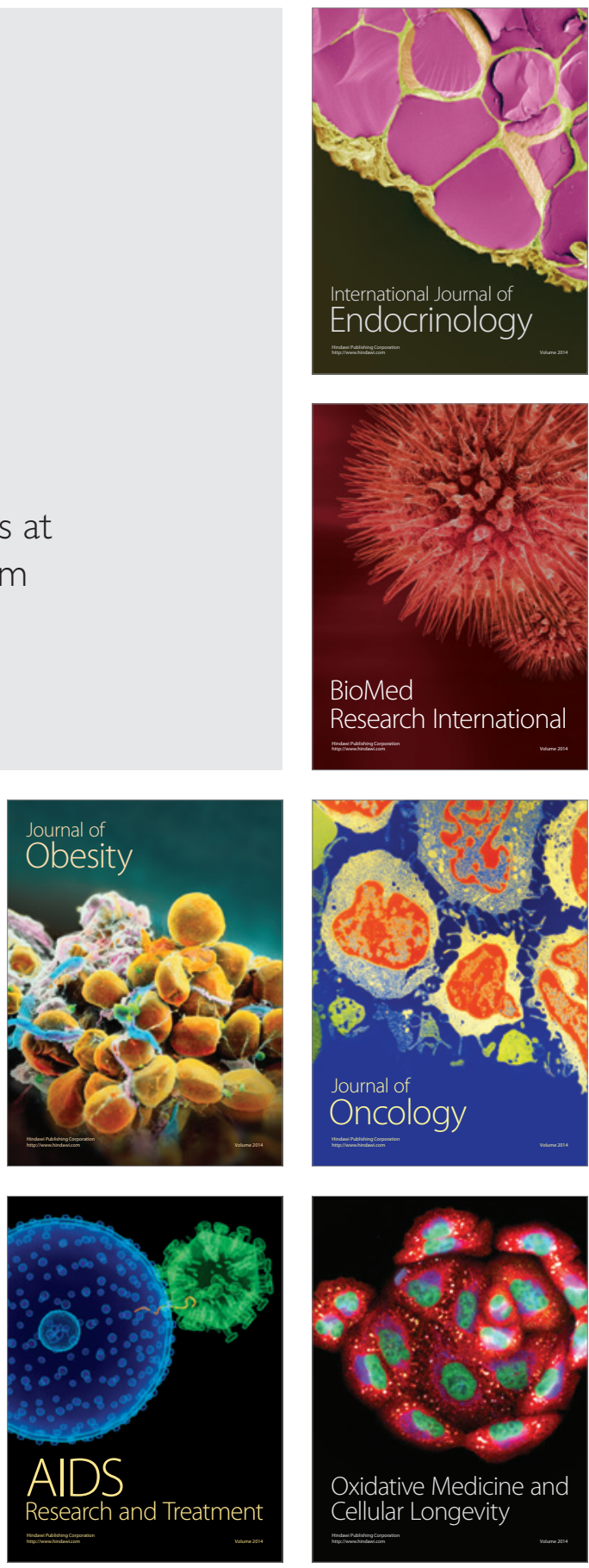